\title{
Maturation of the Small Intestine: Absorption of L-Valine in Rats
}

\author{
M. K. YOUNOSZAI ${ }^{(16)}$ AND K. KOMNICK \\ Department of Pediatrics, Gastroenterology Research Lab, University of Iowa Hospitals and Clinics, \\ Iowa City, lowa, USA
}

\section{Summary}

The in vivo absorption of L-valine was studied in segments of the jejunum and ileum using a one-pass perfusion technique in normal suckling (2-week-old), weanling (3-week-old) and adolescent (6-week-old) rats. In both the jejunum and the ileum, rate of absorption ( $\mu$ moles $/ \mathrm{h} / \mathrm{g}$ wt) of $\mathrm{L}$-valine declined with age. The relationship between absorption rate and luminal concentration suggested the presence both of a saturable carrier mediated $\left(J_{\max }[\mathrm{C}] / K_{t}+[C]\right)$ and diffusive $\left(K_{D} \cdot[C]\right)$ processes for absorption of $L$-valine. In both the jejunum and the ileum, rates 'of carrier mediated and of diffusive absorption of $\mathbf{L}$-valine were over 2 -fold greater in the suckling than in the adolescent rats. Rates of absorption were not significantly different in the jejunum and ileum at all three age periods. Although values of $J_{\max }$ and $K_{D}$ were greater in segments of the suckling rats, values of the apparent $K_{t}$ were similar at all 3 age periods, suggesting that the mechanism (affinity of the carrier macromolecules) of carrier mediated absorption of L-valine did not change with age but the passive permeability of the intestinal mucosa to L-valine and relative number of $L$-valine absorbing sites (number of carrier macromolecules) decreased per unit weight of intestine with increasing age. Serum and intestinal tissue concentration of $l$-valine at the end of the perfusion period were greater in the 2 -week-old than in the older rats. After parentral injection of $\left[{ }^{14} \mathrm{Cl}-\mathrm{L}\right.$-valine rate of secretion of $\mathrm{L}$-valine was several-fold greater in the jejunum and the ileum of the suckling than of the adolescent rats.

\section{Speculation}

The decline in the ability of the small intestine to absorb $L$ valine (per unit weight) with increasing age appears to be due to a decrease in the passive permeability of the mucosal membrane to $L$-valine as well as to a relative decrease in the number of absorbing sites (carrier macromolecules) per unit weight of intestine. The decline in the passive permeability suggests a change in the biochemical composition or the ultrastructure of the mucosal membrane during maturation. The decline in the absorbing capacity of the small intestine with age could be due to a relative increase in number of villus epithelial cells not involved in absorption of amino acid; however, it is more likely to be due to a decrease in number of amino acid absorbing sites (carrier macromolecules) per villus epithelial cell.

The need for amino acid is increased during infancy and childhood compared with the need later in life because infants require amino acids not only for normal body metabolism but also for growth. Per unit body weight, infants consume and also absorb larger amounts of amino acids from proteins than do adults. Greater amounts of amino acids can be absorbed in the intestine during infancy if the absorbing efficiency and/or the relative number of the absorbing sites in the intestine is greater in infants than in adults. Diffusion of amino acid across the intestinal mucosa may also be greater during infancy. Previous in vitro studies comparing absorption of $\mathrm{L}$-valine in pieces of the small intestine obtained from 2-day-old infant and adult rats suggested that the higher rate of absorption of amino acid in the infant intestine could be explained on the basis of a relatively larger number of absorbing sites in the infant as compared to the adult intestine (6). The present studies were performed to determine the postnatal development pattern of the mechanism(s) of absorption of L-valine in vivo along the length of the small intestine in rats.

\section{MATERIALS AND METHODS}

Infant rats were obtained from mothers purchased from Biolabs (St. Paul, MN). After delivery the rat pups were randomized among the mothers and were maintained at 7-9 pups per litter. The mothers were fed a diet containing $26 \%$ casein, $50 \%$ starch, and $15 \%$ sucrose. The diet also contained adequate amounts of minerals and vitamins. The composition of the diet has been published in a previous report (12). After weaning (21 days of age) the pups were maintained on the maternal diet.

The pups were studied when they were suckling (14-15 days), weanling (21-22 days), and adolescent (42-43 days old). At the time of study unfasted rats were anesthetized with intraperitoneal injection of an ethylurea-phenobarbital mixture. After opening the abdominal cavity, about $10-30 \mathrm{~cm}$ long segments of the jejunum (just distal to the ligament of Treitz) and of the ileum (just proximal to the ileocecal junction) were flushed with 20-50 $\mathrm{ml}$ of $145 \mathrm{mM}$ solution of sodium chloride and then with $20 \mathrm{ml}$ of air. Cannulae were inserted at the proximal and distal ends of these segments and tied in place and the small intestine inserted back into the abdominal cavity. Body temperature of the rats was maintained at $36-37^{\circ} \mathrm{C}$ at all times during perfusion. The cannulated segments of the jejunum and ileum were perfused in situ with solutions containing per liter: 120 mmoles of sodium chloride; 3 , $5,15,30,45$, or 60 mmoles of L-valine (Sigma Chemical Company, St. Louis, MO), tracer $\left[{ }^{14} \mathrm{C}\right]-\mathrm{L}$-valine $100,000 \mathrm{dpm} / \mathrm{ml}$, (uniformly labeled $\left[{ }^{14} \mathrm{C}\right]$-L-valine, $0.25 \mathrm{mCi} / 0.12 \mathrm{mg}$, New England Nuclear, Boston, MA), $20 \mathrm{mg}$ of phenol red (as nonabsorbed indicator for volume change), and sufficient mannitol to attain an osmotic pressure of 292-299 m0smoles/kg. Purity of the purchased Lvaline was checked by paper chromatography and no contamination was detected. Five to seven rats at each age period were studied for each concentration of L-valine used. After the start of the perfusion a 45-min period was allowed for attainment of steady state conditions. Perfusates were then collected for the next h during three consecutive 20-min time intervals. At the end of the perfusion period blood was obtained from the aorta. The perfused segments were stripped from the mesentry and their length and wet weight determined. The perfused segments were then cut open along the mesenteric line and the mucosa scraped with the edge of a microscope slide. Weight of the mucosal scrapings and of the underlying tissues were measured and the tissues dried in a vacuum oven for 24 hs at $90-95^{\circ} \mathrm{C}$. The dried tissues were dissolved in $0.5 \mathrm{~N}$ sodium hydroxide solution and alliquots used for determination of $\left[{ }^{14} \mathrm{C}\right]$ radioactivity. Weight and length of the unperfused small intestine excluding the duodenum 
was also measured. Phenol red in the perfusion solutions and perfusates was determined as described by Schedl and Clifton (8). In the perfusion solutions, the perfusates, the aliquots of dissolved tissue and in serum, $\left[{ }^{14} \mathrm{C}\right]$ radioactivity was measured using a Beckman LS 300 Liquid Scintillation Spectrometer.

Disappearance of $\left[{ }^{14} \mathrm{C}\right]$-radioactivity from the lumen during perfusion was taken as indicating net absorption of $L$-valine and calculated as follows: Amount of $\mathrm{L}$-valine absorbed, $\mu$ moles $/ 20$ $\min =\mathrm{V}_{\mathrm{i}}\left([\mathrm{C}]_{\mathrm{i}}-[\mathrm{C}]_{\mathrm{f}} \mathrm{PR}_{\mathrm{i}} / \mathrm{PR}_{\mathrm{f}}\right)$, where $\mathrm{V}$ is volume of the solution perfused through the segments in $\mathrm{ml} / 20 \mathrm{~min}$.; $[\mathrm{C}]$ is the concentration of $\mathrm{L}$-valine $(\mu \mathrm{moles} / \mathrm{ml})$ determined from the radioactivity of $\left[{ }^{14} \mathrm{C}\right]-\mathrm{L}$-valine $(\mathrm{dpm} / \mathrm{ml})$ divided by the specific activity of $\left[{ }^{14} \mathrm{C}\right]$ $-\mathrm{L}$-valine in the perfusion solution as $\mathrm{dpm} / \mu$ mole of $\mathrm{L}$-valine; $\mathrm{PR}$ is concentration of phenol red in the solution in $\mu \mathrm{g} / \mathrm{ml}$; the subscripts $i$ and $f$ refer to the initial values (i) in the perfusion solution and in the perfusates collected (f), respectively. The amount of $\mathrm{L}$-valine absorbed from the intestinal lumen during each of the three 20 -min collection periods was steady and did not vary by more than $13 \%$ of each other. They were added to obtain amount absorbed per $h$. Rate of absorption was expressed on the basis of weight of the perfused segments and weight of the scraped mucosa.

In both the jejunum and ileum the relationship between rate of absorption and concentration of $\mathrm{L}$-valine in the lumen (perfusion solution) was curvilinear (Fig. la), suggesting a saturable carrier mediated mechanism for absorption; however, at the higher luminal concentration the relationship between absorption rate and luminal concentration was linear suggesting also the presence of a diffusive process for absorption. This combined absorptive process was expressed as: $J_{\text {obs }}=J_{\max }[C] / K_{t}+[C]+K_{D}[C]$ where $\mathbf{J}_{\text {obs }}$ represents the observed absorption rate; $J_{\max }[C] / K_{t}+[C]$ the Michaelis-Menton equation describing the carrier mediated process, and $\left(\mathrm{K}_{\mathrm{D}}[\mathrm{C}]\right)$ the diffusive process. $\mathbf{J}_{\max }$ depicts the maximal absorption rate; $[\mathrm{C}]$ the geometric mean luminal concentration of
$\mathrm{L}$-valine in the perfusion fluid before and after perfusion $\sqrt{\left([C]_{i}[C]_{f}\right)} ; K_{t}$ the 'apparent' Michaelis transport constant and $K_{D}$ the diffusion constant of $\mathrm{L}$-valine across the intestinal epithelium. The slope of the straight line passing through points depicting absorption rates from the perfusion solutions containing per liter, $15,30,45$, or 60 mmoles of valine was taken to represent $\mathrm{K}_{\mathrm{D}}$. The diffusive component of absorption $\left(\mathrm{K}_{\mathrm{D}}[\mathrm{C}]\right)$ was calculated and substracted from $\mathrm{J}_{\mathrm{obs}}$ to obtain the values of the carrier mediated component. These values were used to determine $J_{\max }$ and $\mathrm{K}_{\mathrm{t}}$.

Content of absorbed valine in serum $(\mu$ moles $/ \mathrm{ml})$ and intestinal tissues ( $\mu$ moles/g) was calculated from $\left[{ }^{14} \mathrm{C}\right]$ radioactivity in serum $(\mathrm{dpm} / \mathrm{ml})$ and tissues $(\mathrm{dpm} / \mathrm{g})$ divided by the specific activity of $\left[{ }^{14} \mathrm{C}\right]$-L-valine in the perfusion fluid $(\mathrm{dpm} / \mu$ mole of $\mathrm{L}$-valine).

Because absorption of valine was different in infant and adolescent rats, it seemed possible that intestinal secretion of valine could also alter with age. We measured secretion of L-valine into the lumen in separate groups of 5 suckling and 5 adolescent rats. These rats were injected intraperitoneally with $1 \mathrm{ml} / 100 \mathrm{~g}$ body weight of a solution containing per ml: 0.3 mmoles of $\mathrm{L}$-valine and $4 \mu \mathrm{Ci}$ of $\left[{ }^{14} \mathrm{C}\right]-\mathrm{L}$-valine, $2 \mathrm{hs}$ before the study. At the time of study the small intestine was perfused as described above. The composition of the perfusion solution was also similar to the one described above; it contained 5 mmoles/liter of cold L-valine and no radioactive labeled L-valine. After the 105 -min perfusion period, blood was obtained from the aorta and the perfused segments were removed, measured and the mucosal scrapings and underlying tissues were homogenized in $3 \mathrm{ml}$ of $0.5 \mathrm{~N} \mathrm{NaOH}$. Aliquots of perfusion fluid, serum and tissue homogenates were taken for determination of $\left[{ }^{14} \mathrm{C}\right]$ radioactivity.

Rate of appearance of $\left[{ }^{14} \mathrm{C}\right]$ radioactivity in the perfusion solution during perfusion was taken as indicating secretion of valine. Secretion rates as $\mathrm{dpm} / \mathrm{h}$ were calculated using the same formula used for calculation of net absorption rates. In these calculations $[\mathrm{C}]_{\mathrm{i}}$ was zero and $[\mathrm{C}]_{\mathrm{f}}$ represented the $\left[{ }^{14} \mathrm{C}\right]$ radioactivity of the

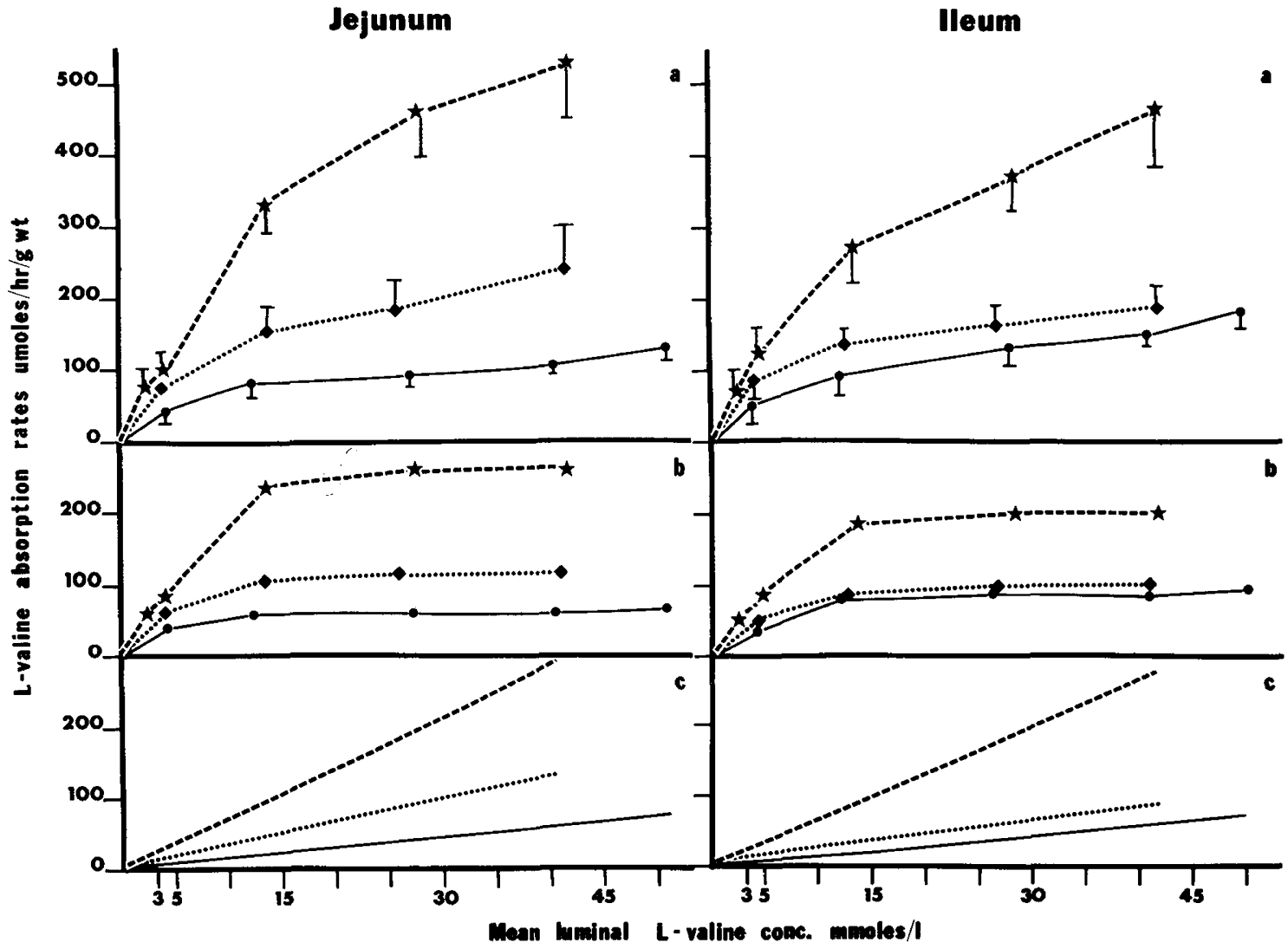

Fig. 1. The relationship between rate of absorption of $\mathrm{L}$-valine in the jejunum and ileum and geometric mean luminal (perfusion solution) concentration of $\mathrm{L}$-valine in suckling (broken lines), weanling (dotted lines) and adolescent (solid lines). The observed absorption rates are shown in panel $a$, the calculated carrier mediated absorption rates in panel $b$, and the calculated diffusive absorption rates in panel $c$. In panel a the bars represent one S.E. of the mean values. Absorption rates in the suckling rats were over 3 -fold greater than corresponding rates in the adolescent rats $(P<0.01)$. 
perfusate as $\mathrm{dpm} / \mathrm{ml}$. Secretion rates were expressed on the basis of weight of the segments perfused.

The statistical significance of the data for the same age group and for the different ages was determined using analysis of variance and the unpaired Student's $t$ test. A $P$ value of less than 0.05 was considered to indicate a statistically significant difference (4).

\section{RESULTS}

Body weight and measurements of the entire small intestine and of the perfused segments of the jejunum and ileum, in the groups of rats at each age period were similar and the data for the corresponding age groups were combined and the mean values of the combined data are shown in Table 1. Longer intestinal segments were used in the older rats to allow perfusion of the same relative region of the intestine. The weight $/ \mathrm{cm}$ ratios of the mucosal scrapings of the perfused segments of the jejunum and of the ileum increased significantly with age. The greater weight $/ \mathrm{cm}$ ratio of the mucosal scrapings in the older than in the younger rats suggested greater absorbing mass per unit length of the jejunum and ileum in the older rats. This was born out in histologic studies of segments of the jejunum and ileum obtained from adolescent and suckling rats, which indicated longer and wider villi in the segments of the older rats. For this reason it would be expected that per unit length of the intestine, adolescent rats would have greater microvillar surface area and thus greater absorbing ability than infant rats. The best parameter for the basis of comparing absorption rates in segments of different size is in the surface area of the microvilli; however, it is not practical to measure microvillar surface area for a large number of segments. The more convenient and next best parameter for the basis of comparing absorption in different segments is the weight of the mucosal scrapings of the segments. Because in the infant rats, 20\% or more of the mucosal scrapings were lost during handling as compared to only $10 \%$ loss in the adolescent rats, rates of absorption were expressed on the basis of wet weight of the segments. Expressing absorption rates on the basis of weight of the mucosal scrapings of the perfused segments (corrected for amount lost) had the same relationship as those based on wet weight of the segments shown in Figure la.

Absorption of $\mathrm{L}$-valine. The observed absorption rates of $\mathrm{L}$ valine, its carrier mediated and diffusive components in the jejunum and ileum of the suckling, weanling and adolescent rats are shown in Figures $1 \mathrm{a}, 1 \mathrm{~b}$ and $1 \mathrm{c}$, respectively. In both the jejunum and the ileum the observed absorption rates were much higher in the suckling than in the older rats. These higher rates were due to higher carrier mediated and diffusive absorption rates. In both segments of the suckling rats absorption rates were over 2-fold greater than in corresponding segments of the adolescent rats. Rates of absorption of $\mathrm{L}$-valine in the jejunal segments were not significantly different than rates of absorption in the corresponding ileal segments, at all 3 age periods.

Table 2 shows the values of $J_{\max }$, and 'apparent' $K_{t}$ for the carrier mediated and $K_{D}$ for the diffusive processes of absorption in the jejunum and ileum of the rats studied. $\mathbf{J}_{\max }$ was about 3fold greater in the suckling than in the adolescent rats, however values of $\mathrm{K}_{\mathrm{t}}$ were similar and not significantly different in the rats at the three age periods. Values for $K_{D}$ were also greater in the segments of the suckling than in those of the adolescent rats. These findings suggested that the carrier mediated mechanism of absorption of valine (the binding of valine to absorbing sites) was the same in the jejunum and the ileum and did not change during development, but that the number of absorbing sites in the intestine decreased with increasing age.

Secretion of $\left[{ }^{14} C\right]-L$-valine. The radioactivity of $\left[{ }^{14} \mathrm{C}\right]-\mathrm{L}$-valine in the serum, intestinal tissues, perfusates and rate of secretion of $\left[{ }^{14} \mathrm{C}\right]-\mathrm{L}$-valine in the rats injected with $\left[{ }^{14} \mathrm{C}\right]-\mathrm{L}$-valine $2 \mathrm{~h}$ before perfusion of the small intestine are shown in Table 3. Although mean radioactivity of $\left[{ }^{14} \mathrm{C}\right]-\mathrm{L}-\mathrm{valine}$ in serum was only slightly lower in the suckling than in the adolescent rats, intestinal tissue $\left[{ }^{14} \mathrm{C}\right]$ radioactivity was significantly and over 2 -fold greater in the suckling than in the adolescent rats. In the perfusates, at the end of the perfusion period $\left[{ }^{14} \mathrm{C}\right]$ radioactivity $(\mathrm{dpm} / \mathrm{ml})$ was similar in the suckling and adolescent rats; however, the secretion rate of $\left[{ }^{14} \mathrm{C}\right]-\mathrm{L}$-valine $(\mathrm{dpm} / \mathrm{h} / \mathrm{g}$ weight of segments) was over 8 -fold greater in the jejunum and about 16-fold greater in the ileum of the suckling than in the corresponding segments of the adolescent rats.

Tissue content of $L$-valine. The content of absorbed L-valine in the mucosal scrapings and in the underlying tissues of the perfused segments of the jejunum and ileum, and in the serum of the rats perfused with solutions containing $5,15,30$, and 45 mmoles of $\mathrm{L}$ valine are shown in Table 4 . In the suckling rats blood and tissue content were significantly higher than corresponding values in the

Table 2. Values of $J_{\max }$ (maximal absorption rate) and of $K_{t}$ (Michealis transport constant) for the carrier mediated and $K_{D}$ (diffusion constant) for the diffusive processes of absorption in the jejunum and ileum of suckling, weanling and adolescent rats

\begin{tabular}{lccc}
\hline \multicolumn{1}{c}{ Rats } & Suckling & Weanling & Adolescent \\
\hline Segments perfused, jejunum & & & \\
$\mathbf{J}_{\max }(\mu$ moles/h/g wt) & 250 & 108 & 65 \\
$\mathrm{~K}_{\mathrm{t}}$ (mmoles) & 5.8 & 4.2 & 4.0 \\
$\mathrm{~K}_{\mathrm{D}}$ & 7.14 & 3.27 & 1.80 \\
Segments perfused, ileum & & & \\
$\mathbf{J}_{\max }(\mu$ moles/h/g wt) & 200 & 100 & 85 \\
$\mathrm{~K}_{\mathrm{t}}(\mathrm{mmoles})$ & 5.0 & 4.0 & 5.5 \\
$\mathrm{~K}_{\mathrm{D}}$ & 6.80 & 2.41 & 1.28 \\
\hline
\end{tabular}

Table 1. Age, body weight and measurements of the total small intestine and of the perfused segments of the jejunum and ileum in the rats studied $^{1}$

\begin{tabular}{lccc}
\hline \multicolumn{1}{c}{ Rats } & Suckling & Weanling & Adolescent \\
\hline No. studied & 35 & 33 & 34 \\
Body weight & $33 \pm 2$ & $49 \pm 3$ & $239 \pm 5$ \\
Total small intestine & & & $57 \pm 3$ \\
$\quad$ Length (cm) & $38 \pm 1$ & $1.98 \pm 0.10$ & $86 \pm 2$ \\
$\quad$ Weight (g) & $0.79 \pm 0.18$ & & $6.72 \pm 0.26$ \\
Segments perfused & & & $17 \pm 1$ \\
$\quad$ Jejunum & $11 \pm 1$ & $646 \pm 20$ & $26 \pm 1$ \\
$\quad$ Length (cm) & $263 \pm 15$ & $20.5 \pm 1.9$ & $2153 \pm 165$ \\
$\quad$ Wet weight (mg) & $10.5 \pm 1.2$ & & \\
$\quad$ Mucosal scraping (mg/cm) & $14 \pm 1$ & $20 \pm 2$ & 2.7 \\
$\quad$ Ileal & $294 \pm 16$ & $642 \pm 18$ & $1523 \pm 186$ \\
$\quad$ Length (cm) & $9.1 \pm 1.3$ & $18.1 \pm 2.0$ & $39.4 \pm 3.0$ \\
$\quad$ Wet weight (mg) & & & \\
$\quad$ Mucosal scraping (mg/cm) & & \\
\hline
\end{tabular}

\footnotetext{
${ }^{1}$ Values are mean \pm S.E.
} 
weanling and adolescent rats $(P<0.05)$. In the suckling rats tissue content of absorbed L-valine did not alter with increasing lumen concentration of $\mathrm{L}$-valine. In the weanling and adolescent rats tissue content of absorbed $\mathrm{L}$-valine increased with concentration of $\mathrm{L}$-valine in the lumen (perfusion solution). Content of L-valine in serum was higher in suckling than older rats $(P<0.05)$. The serum content of $\mathrm{L}$-valine did not appear to change with increasing luminal concentration of $\mathrm{L}$-valine.

\section{DISCUSSION}

These in vivo studies indicated that regardless of the developmental stage of the intestine, absorption of valine in the jejunum and ileum occurred both by saturable carrier mediated and by diffusive processes. The saturable carrier mediated process implies involvement of carrier macromolecules located in the brush border

Table 3. Radioactivity of $\left[{ }^{14} C\right]-L$-valine in serum, intestinal tissues, lumen, and rate of secretion of $\left[{ }^{14} C\right]-L$-valine in the perfused segments of the jejunum and ileum of the suckling and the adolescent rats studied ${ }^{1}$

\begin{tabular}{lcc}
\hline \multicolumn{1}{c}{ Rats } & Suckling & Adolescent \\
\hline $\begin{array}{l}{\left[{ }^{14} \mathrm{C}\right]-\mathrm{L}-\mathrm{v} \text { aline concentration }} \\
\text { (dpm/ml or g wet wt) }\end{array}$ & & \\
Serum & & \\
Jejunal & $27240 \pm 3105$ & $35702 \pm 4520$ \\
$\quad$ Underlying tissue & $14541 \pm 2232$ & $5664 \pm 840^{2}$ \\
$\quad$ Mucosal scrapings & $13082 \pm 2106$ & $2058 \pm 533^{2}$ \\
$\quad$ Lumen & $478 \pm 98$ & $530 \pm 58$ \\
Ileal & $16297 \pm 2686$ & $5542 \pm 794^{2}$ \\
$\quad$ Underlying tissue & $19653 \pm 3057$ & $3222 \pm 526^{2}$ \\
$\quad$ Mucosal scrapings & $632 \pm 83$ & $412 \pm 55$ \\
$\quad$ Lumen & & \\
{$\left[{ }^{14} \mathrm{C}\right]-\mathrm{L}-\mathrm{valine}$ secretion } & & \\
(dpm/g wet wt/h) & & \\
$\quad$ Jejunum & & \\
$\quad$ lleum & $91755 \pm 7250$ & $2314 \pm 458^{2}$ \\
\hline
\end{tabular}

${ }^{1}$ These rats were injected intraperitoneally with a solution containing $\left[{ }^{14} \mathrm{C}\right]$-L-valine $2 \mathrm{~h}$ before intestinal perfusion. Values are mean \pm S.E.

${ }^{2}$ Mean values in adolescent rats significantly different than corresponding values in suckling rats $P<0.05$. membrane of the enterocytes, which bind and translocate $\mathrm{L}$-valine across the brush border membrane from the lumen into the cell interior. Both the number per unit mucosal surface area, and affinity (binding characteristics for L-valine) of these macromolecules can alter absorption rate. The location of such macromolecules in the brush border membrane may be considered as sites where valine is absorbed by the carrier mediated process. The diffusive process of absorption of L-valine is poorly understood; however, diffusion can occur through the "tight junctions" between cells or through cell membranes.

At the lower luminal concentrations, which are probably more in the physiologic range, the carrier mediated process appeared to be the main mode of absorption. At the higher luminal concentration the magnitude of amount absorbed by diffusion became as great as amount absorbed by carrier mediation (Fig. 1).

In the rats studied, the maturation of the small intestine appeared to be associated with changes in both the carrier mediated and diffusive processes of absorption of $L$-valine. The net effect of these changes was a decline in the ability to absorb amino acid with increasing age. In both the jejunum and in the ileum the magnitude of the carrier mediated absorptive process decreased 2fold before the time of weaning. After weaning there was a further but slower decline in the absorptive processes. The decline does not appear to have been due to a significant decrease in surface area of the mucosa per unit weight of intestine with age.

In microscopic histology of the intestine, the villi appear longer and the number of epithelial cells lining the villi appear more numerous in adolescent than in suckling rat intestine. Because the morphology of the cells and dimensions of the microvilli appear similar in suckling and adolescent rats it would be expected that per unit length of intestine the number of cells in the mucosa and the mucosal surface area would be greater in older than in young rats. In fact the gross mucosal surface area of the intestine expressed as $\mathrm{cm}^{2} / \mathrm{cm}$ has been shown to be greater in adult than in young rats (5). This greater surface area is associated with greater weight $/ \mathrm{cm}$ ratio of the full thickness wall of the intestine and also of its mucosal scrapings (Table 1). Because water content of the intestine is similar in infant and older rats, weight of the intestine may be taken to represent total number of cells in the intestine, and the greater weight $/ \mathrm{cm}$ in older than in infant rats (Table 1) would represent a greater number of cells $/ \mathrm{cm}$ of intestine in the older rats. Because the number of epithelial cells as \% of total intestinal cells is similar in infant and adult rats, amounting to

Table 4. Concentration of absorbed $L$-valine ${ }^{1}$ in serum and in tissues of segments of the jejunum (J) and ileum (IL) in suckling, weanling and adolescent rats perfused with the solutions containing 5,15 , 30, or 45 mmoles of $L$-valine and tracer $\left[{ }^{14} C\right]-L$-valine ${ }^{2}$

\begin{tabular}{|c|c|c|c|c|c|c|}
\hline \multirow{2}{*}{$\begin{array}{l}\text { Rats } \\
\text { Perfused segment }\end{array}$} & \multicolumn{2}{|c|}{ Suckling } & \multicolumn{2}{|c|}{ Weanling } & \multicolumn{2}{|c|}{ Adolescent } \\
\hline & $J$ & IL & $\mathbf{J}$ & IL & $J$ & IL \\
\hline \multicolumn{7}{|c|}{ Valine concentration $(\mu$ mole/g or $\mathrm{ml})$} \\
\hline Perfusion solution & \multicolumn{2}{|c|}{5} & \multicolumn{2}{|c|}{5} & \multicolumn{2}{|c|}{5} \\
\hline Mucosa scraping & $11.7 \pm 2.3$ & $10.2 \pm 2.2$ & $4.6 \pm 0.4$ & $5.0 \pm 0.6$ & $2.7 \pm 0.3$ & $2.4 \pm 0.2$ \\
\hline Underlying tissues & $10.5 \pm 1.9$ & $11.1 \pm 1.8$ & $4.8 \pm 0.5$ & $4.9 \pm 0.8$ & $2.9 \pm 0.4$ & $2.5 \pm 0.3$ \\
\hline Serum & \multicolumn{2}{|c|}{$3.5 \pm 0.5$} & \multicolumn{2}{|c|}{$2.5 \pm 0.4$} & \multicolumn{2}{|c|}{$2.1 \pm 0.2$} \\
\hline Perfusion solution & \multicolumn{2}{|c|}{15} & \multicolumn{2}{|c|}{15} & \multicolumn{2}{|c|}{15} \\
\hline Mucosa scraping & $10.2 \pm 1.3$ & $11.9 \pm 1.3$ & $4.8 \pm 0.9$ & $6.4 \pm 1.8$ & $4.4 \pm 0.5$ & $5.2 \pm 0.9$ \\
\hline Underlying tissues & $12.4 \pm 2.0$ & $13.2 \pm 0.8$ & $5.4 \pm 1.0$ & $5.1 \pm 1.8$ & $5.9 \pm 1.1$ & $5.2 \pm 0.4$ \\
\hline Serum & \multicolumn{2}{|c|}{$4.0 \pm 0.9$} & \multicolumn{2}{|c|}{$3.5 \pm 0.5$} & \multicolumn{2}{|c|}{$2.3 \pm 0.4$} \\
\hline Perfusion solution & \multicolumn{2}{|c|}{30} & \multicolumn{2}{|c|}{30} & \multicolumn{2}{|c|}{30} \\
\hline Mucosa scraping & $10.4 \pm 0.5$ & $11.8 \pm 0.5$ & $8.8 \pm 1.1$ & $11.0 \pm 0.9$ & $7.6 \pm 0.8$ & $5.4 \pm 1.3$ \\
\hline Underlying tissues & $13.8 \pm 1.3$ & $14.15 \pm 1.1$ & $7.9 \pm 0.8$ & $9.5 \pm 0.5$ & $5.8 \pm 0.6$ & $4.9 \pm 0.8$ \\
\hline Serum & \multicolumn{2}{|c|}{$4.1 \pm 0.9$} & \multicolumn{2}{|c|}{$2.5 \pm 0.5$} & \multicolumn{2}{|c|}{$2.4 \pm 0.1$} \\
\hline Perfusion solution & \multicolumn{2}{|c|}{45} & \multicolumn{2}{|c|}{45} & \multicolumn{2}{|c|}{45} \\
\hline Mucosa scraping & $10.7 \pm 0.9$ & $16.5 \pm 1.3$ & $8.7 \pm 1.0$ & $10.9 \pm 1.2$ & $7.3 \pm 0.3$ & $8.5 \pm 1.8$ \\
\hline Underlying tissues & $9.9 \pm 0.3$ & $19.8 \pm 2.9$ & $9.1 \pm 0.6$ & $10.9 \pm 1.0$ & $7.2 \pm 0.4$ & $7.6 \pm 0.7$ \\
\hline Serum & \multicolumn{2}{|c|}{$4.8 \pm 1.2$} & \multicolumn{2}{|c|}{$2.2 \pm 0.3$} & \multicolumn{2}{|c|}{$2.4 \pm 0.5$} \\
\hline
\end{tabular}

${ }^{1} \mathrm{~L}$-valine concentration was calculated from tissue or serum $\left[{ }^{14} \mathrm{C}\right]$-radioactivity $\mathrm{dpm} / \mathrm{g}$ or $\mathrm{ml}$, divided by specific activity of $\left.{ }^{14} \mathrm{C}\right]-\mathrm{L}-\mathrm{valine}$ in perfusion solution $\mathrm{dpm} / \mu$ mole of $\mathrm{L}$-valine.

${ }^{2}$ Values are mean \pm S.E. 
$53.6 \%$ in infant, $30 \mathrm{~g}$ rats and to $48.4 \%$ in adult, $300 \mathrm{~g}$ rats (1), it would be expected that per unit weight of intestine the epithelial cell number and the mucosal surface area are about the same in infant and adolescent rats. Hence the marked changes in values of $\mathbf{J}_{\max }$ (Table 3 ) with age does not appear to have been caused by marked changes in surface area of the mucosa. The decline in rate of absorption was most probably due to a relative decrease in the number of carrier mediated transport sites per unit weight (surface area) of the intestine. Because values of $K_{t}$ did not change significantly with age (Table 3 ) it may be assumed the affinity of the carrier mediated absorptive process for $\mathrm{L}$-valine in the intestine remained fairly constant at the 3 age periods studied.

The reason for the apparent decrease in number of carrier mediated absorpting sites is not known, but could be due to a decrease in number of carrier mediated absorpting sites per cell or due to a dilution of epithelial cells absorbing valine by those not absorbing valine. The latter possibility appears unlikely.

Similar to the carrier mediated absorption, the diffusive absorption of $L$-valine in the jejunum and ileum also declined with age, with the major decline again occurring before the time of weaning. The reason for this decline is again not understood, but cannot be explained on the basis of major differences in mucosal surface at the 3 age periods. The greater diffusion during suckling could be related to the general tendency of the permeability of the small intestinal mucosa to water, and electrolytes, including calcium to decrease with increasing age $(13,14,15)$.

The greater permeability of the intestinal mucosa to valine in infant than in older rats appeared to be bidirectional. Not only rate of absorption but rate of secretion of $\left[{ }^{14} \mathrm{Cl}-\mathrm{L}\right.$-valine was several fold greater in the suckling than adolescent rats (Table 3). It is unlikely that the differences in rate of secretion of L-valine in segments of suckling and adolescent rats was due to differences in an active or carrier mediated process of secretion.

The route of passive diffusion of $L$-valine across the intestinal epithelium is not known but could be through the tight junctions of through the lipid membranes of the brush border. Christiansen and Reiser (2) have suggested the formation of a complex between L-valine and the lipids of the brush border membrane and have speculated that it could be involved in absorption of $L$-valine. If the latter is true, it suggests that the composition of the lipids of the brush border membrane of villus epithelial cells alter during development; most of the change occurring before the time of weaning.

Results of previous in vitro studies of tissue uptake of L-valine by pieces of the small intestine $(3,6)$ are quite similar to those found in the present in vivo studies. The apparent Michealis constant for valine transport found in everted sacs of the adult rat intestine by Reiser and Christiansen (6) was $2.89 \mathrm{mM}$ in one study and in another study the apparent $\mathrm{K}_{\mathrm{m}}$ values were $5.9 \mathrm{mM}$ for the intestine of 2-day-old rats and $6.8 \mathrm{mM}$ for the intestine of adult rats (7). In the present in vivo study the Michealis transport constant was $4.2-5.5 \mathrm{mM}$ for the segments of suckling, weanling and adolescent rats. In biopsies of the small intestine obtained from adult humans the apparent $K_{m}$ values for absorption of valine was found to be $9.1 \mathrm{mM}$ in obese subjects and 4.6 in normal subjects (9). Again values close to those found in the present in vivo and in the previous in vitro rat studies.

It has been pointed out that the apparent $\mathrm{K}_{\mathrm{m}}$ values obtained in in vivo studies are greater in magnitude than the true $\mathrm{K}_{\mathrm{m}}$ values $(10,11)$. In an in vivo system of perfusion as that used in the present study, rate of perfusion has to be greater than $1 \mathrm{ml} / \mathrm{min}$ before an effect on absorption is noticeable. In the present study the pump rate used was low $(0.25 \mathrm{ml} / \mathrm{min})$ and not expected to have significantly altered unstirred layers in the segments per- fused; however, because of larger diameter of the intestine in adolescent rats the volume of fluid passing through the lumen as $\mathrm{ml} / \mathrm{cm}$ length of the segments was lower in adolescent than in suckling rats. This slower passage of perfusion fluid could have affected the absorption rate. To test this possibility segments of the jejunum and ileum, in a group of five adolescent rats, were perfused with the solution containing $60 \mathrm{mmoles} /$ liter of L-valine at the rate of $0.9 \mathrm{ml} / \mathrm{min}$. This over 3 -fold increase in rate of perfusion did not significantly increase absorption rate. Thus differences in size of intestine and perfusion rate did not appear to have been responsible for the marked differences in absorption rate at the 3 age periods.

The higher absorption rates in the suckling than in the older rats could have caused the higher blood and intestinal tissue levels of $\left[{ }^{14} \mathrm{C}\right]-\mathrm{L}$-valine radioactivity in the suckling rats; however, higher $\left[{ }^{14} \mathrm{C}\right]$-L-valine radioactivity in serum and intestinal tissues was also noted after intraperitoneal injection of $\left[{ }^{14} \mathrm{C}\right]$-L-valine (Table 4). Thus the higher blood and tissues levels of $\left[{ }^{14} \mathrm{C}\right]-\mathrm{L}$-valine appeared to have been an innate property of infant rat tissues and not related to absorption rate of $\mathrm{L}$-valine. This is also born-out in the finding that although rate of absorption of $\mathrm{L}$-valine increased several fold with increase in perfusion solution $\mathrm{L}$-valine concentration, serum and tissue levels of $\left[{ }^{14} \mathrm{C}\right]-\mathrm{L}-\mathrm{valine}$ remained relatively constant in the suckling rats. In the weanling and adolescent rats although, serum levels of $\left[{ }^{14} \mathrm{C}\right]-\mathrm{L}$-valine remained constant, tissue levels increased with increase in perfusion solution L-valine concentration probably reflecting differences in turn over rates or size of pool(s) of the amino acid in the tissue of the rats at the three age periods.

\section{REFERENCES AND NOTES}

1. Altmann, G. G. and Enesco, M.: Cell number as a measure of distribution and renewal of epithelial cells in the small intestine of growing and adult rats. Am. J. Anat., 121: 319 (1967).

2. Christiansen, P. A. and Reiser, S.: Formation of a complex between valine and intestinal mucosal lipid; its possible role in valine absorption. J. Lipid Res., 9: 606 (1968).

3. Fitzgerald, J. F., Reiser, S., and Christiansen, P. A.: Developmental pattern of sugar and amino acid transport in the postnatal rat small intestine. Pediatr. Res., 5: 698 (1971).

4. Huntsberger, D. V. and Leaverton, P. E.: Statistical inference in the biomedical sciences. Allyn and Bacon, Inc., Boston (1970).

5. Penzes, L. and Skala, I.: Changes in the mucosal surface area of the small gut of rats of different ages. J. Anat., 124: 217 (1977).

6. Reiser, S. and Christiansen, P. A.: Intestinal transport of amino acids studied with L-valine. Am. J. Physiol., 208: 914 (1965).

7. Reiser, S., Fitzgerald, J. F., and Christiansen, P. A.: Kinetics of the accelerated intestinal valine transport in 2-day-old rats. Biochim. Biophys. Acta, 203: 351 (1970).

8. Schedl, H. P. and Clifton, J. A.: Small intestinal absorption of steroids. Gastroenterology, 41: 491 (1961).

9. Steiner, M., Bourges, H. R., Farrish, G. C. M., Ross, J. R., and Gray, S. J.: Intestinal uptake of valine in obesity. Amer. J. Med. Sci., 257: 234 (1969).

10. Thomson, A. B. R.: Limitations of Michealis-Menton kinetics in presence of intestinal unstirred layers. Am. J. Physiol., 236: E701 (1979).

11. Winne, D., Kopf, S., and Ulmer, M.: Role of unstirred layer in intestinal absorption of phenylalanine in vivo. Biochim. Biophys. Acta, 550: 120 (1979).

12. Younoszai, M. K. and Ranshaw, J.: Gastrointestinal growth in fetus and suckling rat pups: effects of maternal dietary protein. J. Nutr., 103:454 (1973).

13. Younoszai, M. K.: In vivo transport of water and electrolytes in the infant rat small intestine. Proc. Soc. Exper. Biol. Med., 160: 192 (1979).

14. Younoszai, M. K. and Robillard, J. E.: In vivo intestinal bicarbonate transport in infant rats. Pediatr. Res. 14: 839 (1980).

15. Younoszai, M. K., Ghishan, F. K., and Jenkins, J. T.: Maturation of calcium transport in the small and large intestine. J. Nutr., 110: 1622 (1980).

16. Requests for reprints should be addressed to: Dr. M. K. Younoszai, University of Iowa Hospitals and Clinics, Department of Pediatrics, Iowa City, Iowa, USA

17. Received for publication October $21,1981$.

18. Accepted for publication March 5, 1982. 